\title{
Optimal Placement and Size of Distributed Generators Based on Autoadd and PSO to Improve Voltage Profile and Minimize Power Losses
}

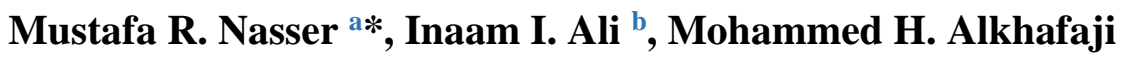 \\ ${ }^{a}$ Electrical Engineering Department, University of Technology, Baghdad, Iraq. \\ 316210@ student.uotechnology.edu.iq \\ ${ }^{\mathrm{b}}$ Electrical Engineering Department, University of Technology, Baghdad, Iraq. \\ Inaam.i.ali@uotechnology.edu.iq
}

${ }^{c}$ Electrical Engineering Department, University of Technology, Baghdad, Iraq. 30072@uotechnology.edu.iq *Corresponding author.

$\begin{array}{lll}\text { Submitted: 31/07/2020 Accepted: 22/10/2020 Published: 25/03/2021 } & \text { Accer }\end{array}$

\section{K E Y W O R D S}

Loss minimization, optimal placement, Autoadd, PSO, DG integration

\begin{abstract}
A B S T R A C T
This work aims to improve the voltage profile and reduce electrical network losses through optimal planning of distributed generators. A new search algorithm (Autoadd) along with the (PSO) are introduced to choose the best location and size for distributed generators. Two systems are implemented; a 33-bus test network and a 30-bus of a local community in the city of Al-Diwaniyah. At the power flow, a solution is implemented using a fixed-point iteration method within an OpenDSS environment to check the performance of both networks. Moreover, the optimal location and size of the distributed generators are determined using Autoadd and PSO methods. The Autoadd method is implemented within the OpenDSS environment, while the (PSO) method is implemented within the MATLABOpenDSS environment through the com-interface. The validity and effectiveness of the proposed methods are validated by comparison with the published researches. The results have proven that the fixed-point method has achieved high efficiency and accuracy in terms of analyzing the power flow, whereas the (Autoadd) algorithm has achieved a better effect in terms of improving the voltage profile and minimizing losses.
\end{abstract}

\footnotetext{
How to cite this article: M. R. Nasser, I. I. Ali and M. H. Alkhafaji, "Optimal Placement and Size of Distributed Generators Based on Autoadd and PSO to Improve Voltage Profile and Minimize Power Losses,” Engineering and Technology Journal, Vol. 39, Part A, No. 03, pp. 453-464, 2021.

DOI: https://doi.org/10.30684/etj.v39i3A.1781

This is an open access article under the CC BY 4.0 license http://creativecommons.org/licenses/by/4.0
}

\section{INTRODUCTION}

The distribution systems suffer from high voltage drops, high power loss, and low voltage stability, in addition to the constantly increasing demand [1,2]. At present, these issues have led to 
increasing interest in the distributed generators in the generation and transportation sectors [3]. Distributed Generators (DGs) are gaining importance in the energy market because of their high reliability and efficiency and as a promising way to reduce stress on transmission and distribution lines [4]. Integrating distributed generators within traditional networks makes the power flow bidirectionally within the network. Therefore, DGs have to be integrated after extensive planning to avoid adverse impacts in the networks [5]. The common and most used way to reduce losses and to improve voltage profile is to determine the optimal location and size of DGs over the network [6].

Some literature concerns the optimal layout of distributed generators as follows. Ullah et al. have suggested an analytical approach determine the optimum location and size of distributed generators using (PSO) and (PPSO) method to reduce losses and improve the voltage profile [7]. Montoya et al. have proposed a general algebraic modeling system (GAMS) with a BONMIN solver in which the problem was diagnosed as a mixed-integer nonlinear programming (MINLP) to define the optimal location and size of DGs [3]. Essallah et al. have presented a new method for optimal planning of DGs where researchers used the Voltage -Stability Margin- Index (VSMI) method to determine the optimum location and determine the size by MATLAB -curve- fitting -approximation [8]. Magadum and Kulkarni have proposed the fuzzy logic method to determine the optimal location and size of DGs [9]. Researches [6 and 10], have proposed the genetic algorithm for the optimal planning of DGs. Davda and Parekh studied the effect of incorporation of DGs on the distribution network. Their methodology was developed in CYMDIST to limit the optimal location and size of DGs [11].

This work focuses on analyzing the power flow based on a fixed-point iteration method within an OpenDSS environment and on reducing power losses. It improves the voltage profile in the distribution network based on the selection of the optimal location and size of DGs through the application of AutoAdd and PSO strategies. PSO algorithm implements through the OpenDSS program within the MATLAB environment. While the Autoadd algorithm applied directly to the standalone OpenDSS program. Figure 1 shows the structure of the presented workflow.

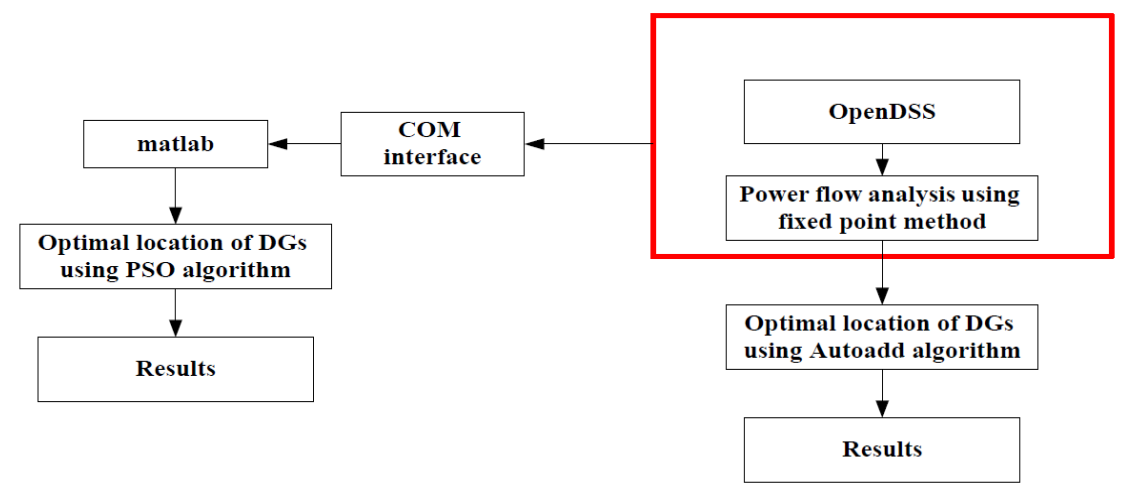

Figure 1: The structure of the presented workflow

\section{Proposed Methodology}

\section{Power Flow Method}

The fixed-point iteration algorithm is the standard solution method in OpenDSS software. This algorithm solves the power flow to the distribution networks iteratively by constructing a nodal admittance matrix [12]. This algorithm differs from the traditional methods used to solve the energy flow, such as Newton Raphson and Gauss Seidal because it does not use the energy data that is directly injected into the system. Where it creates (admittance matrix) for the elements of the power distribution system. Power conversion elements (generators and loads) are designed as Norton's equivalents with a constant admittance matrix (Yprim) and a compensation current Icomp (inj) to compensate the nonlinear part, as shown in Figure 2. 


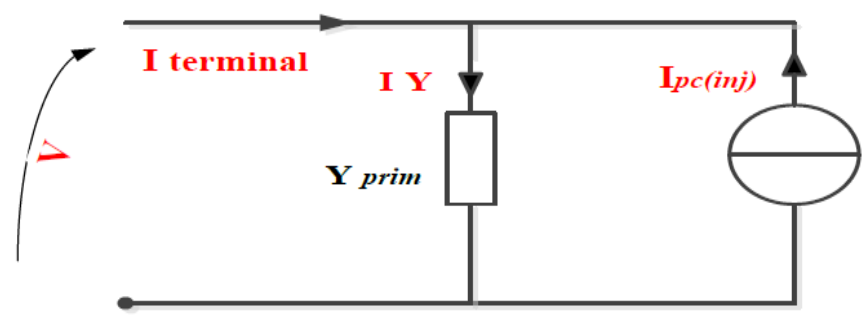

Figure 2: Power conversion element (PC) model [13]

The algorithm of energy flow analysis is described as follows [13, 14]:

1) Before starting the power flow algorithm, OpenDSS finds the system's nodal admittance matrix. Then remove all the power conversion (PC) elements from the network. Calculate the node voltages initial $\left(\mathrm{V}_{0}\right)$ value for iterations with the system admittance $\left(\mathrm{Y}_{\mathrm{system}}\right)$ in this form, as shown in Eq. (1):

$$
V_{\text {a..n }}^{0}=\left[Y_{\text {system }}\right]^{-1} \times \text { Isource }
$$

2) Add all the (PC) elements to the system. Calculate the compensation (injection) current (I comp, inj) of each (PC) element with its ( $\mathrm{Y}_{\text {system }}$, node voltages, and power.

From Figure 2, the compensation current (I comp) is the difference between the current drawn by the nonlinear power conversion element and the linear portion of the element, if any that is embedded in the $\mathrm{Y}_{\text {system }}$ matrix, as shown in Eq. (2):

$$
I_{\text {comp }, \text { inj }}^{k}=I_{y}^{k}-I_{\text {terminal }}^{k}
$$

3) Use the $\left(\mathrm{I}_{\mathrm{comp}, \mathrm{inj}}\right)$ from each (PC) element to form a compensation current matrix. Node voltages can be calculated with the compensation current matrix and the ( $\left.\mathrm{Y}_{\text {system }}\right)$ matrix through matrix operations, as shown in Eq. (3):

$$
\left[\begin{array}{c}
V_{a}^{k} \\
\cdot \\
\cdot \\
V_{n}^{k}
\end{array}\right]=\left[Y_{\text {system }}\right]^{-1} \times\left[\begin{array}{c}
I_{\text {source }} \\
\cdot \\
\cdot \\
I_{\text {comp }, \text { inj }}^{k}
\end{array}\right]
$$

4) Convergence test, keep repeating until the node effort error occurs in the tolerance, as shown in Eq. (4):

$$
\text { error }_{a . . n}^{k}=\frac{V_{a . . n}^{k}-V_{a . n}^{k-1}}{V_{\text {source }}}
$$

Where(Isource): source current, $(k)$ : number of iteration, $\left(\mathrm{V}_{\text {source }}\right)$ : source voltage, $\left(\mathrm{V}_{\mathrm{a} . . \mathrm{n}}\right)$ : node voltage, $\left(\mathrm{I}_{\text {terminal }}\right)$ : terminal current (from the network), $\mathrm{I}_{\mathrm{y}}^{\mathrm{k}}$ : current drawn by the nonlinear power conversion element, Ipc, comp, inj $(\mathrm{V})=$ compensation, or injection, currents from Power Conversion (PC) elements in the circuit, which may be nonlinear elements, $n=1,2, \ldots 3$ : number of iteration. Figure 3 shows a summary of the working steps of the algorithm 


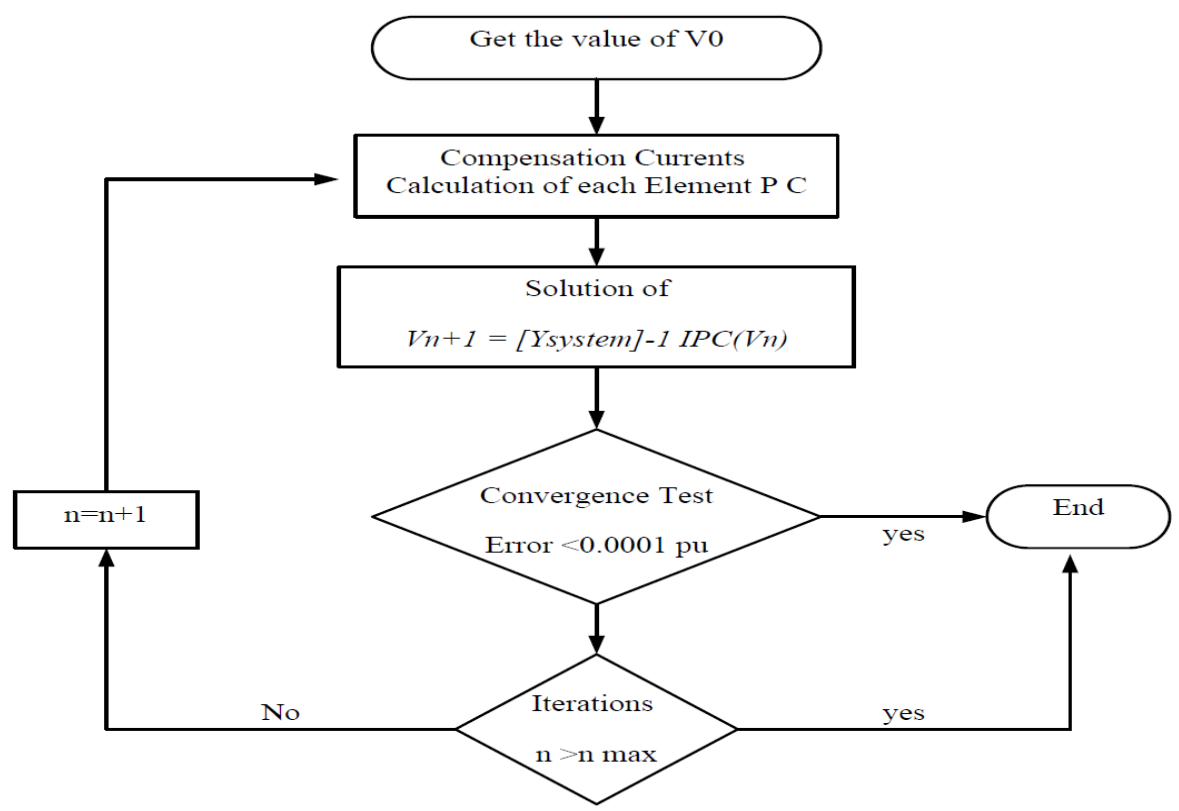

Figure 3: Flowchart of the fixed-point iterative solution algorithm

\section{Autoadd optimization algorithm}

In this work, a new search algorithm (Autoadd) is used for the optimal layout of distributed generators. Autoadd is an internal automatic feature of OpenDSS for optimizing the location of generators and capacitors [12]. The problem of optimization of distribution system analysis as equation (5) [15].

$$
\begin{gathered}
\operatorname{Min} f(x, u)=P_{L} \\
\text { Subject }-\operatorname{tog} g(x, u)=0 \\
0.95<=V i<=1.05
\end{gathered}
$$

Where $g(x, u)=0$ is the equation of the distribution power flow. $V i$ is the voltage on the bus (ith). Equation (5) specifies the amount of active and reactive injection power per node to reduce system losses base on the fixed-point method. Then, the data is automatically recorded in the Autoadd mode by the energy meter object of the OpenDSS software. This feature benefits from direct access to the injected currents (I (comp, inj)) equations (2 and 3) quickly without rebuilding (Ysystem) for each test location [13, 14]. In order to transfer the generators from one bus to another, the program searches each available bus for a location that gives the greatest per unit improvement in a combination of losses and capacity on the Eq. (6):

$$
\text { Minimize (loss weight } * \text { losses }+U E \text { weight } * U E)
$$

Where loss weight: Weighting factor for Losses in AutoAdd functions, UE weight: weighting factor for Unserved Energy (UE)/ Energy Exceeding Normal (EEN)

UE refers to load energy considered unserved because the power (actually the current) exceeds Emergency, or maximum, ratings. EEN refers to load energy considered unserved because the current or voltage exceeds normal ratings.

Also, in this algorithm, the convergence velocity of the solution increases (6 seconds) because the admittance matrix of the system does not change. Usually, the solution to find the location of each generator takes (2-4) iterations (in each solution) and the results are shown as a percentage factor per bus. The percentage improvement factor shows the next best location to supply powers [15].

Figure 4 shows the Autoadd optimization algorithm to reduce losses. 


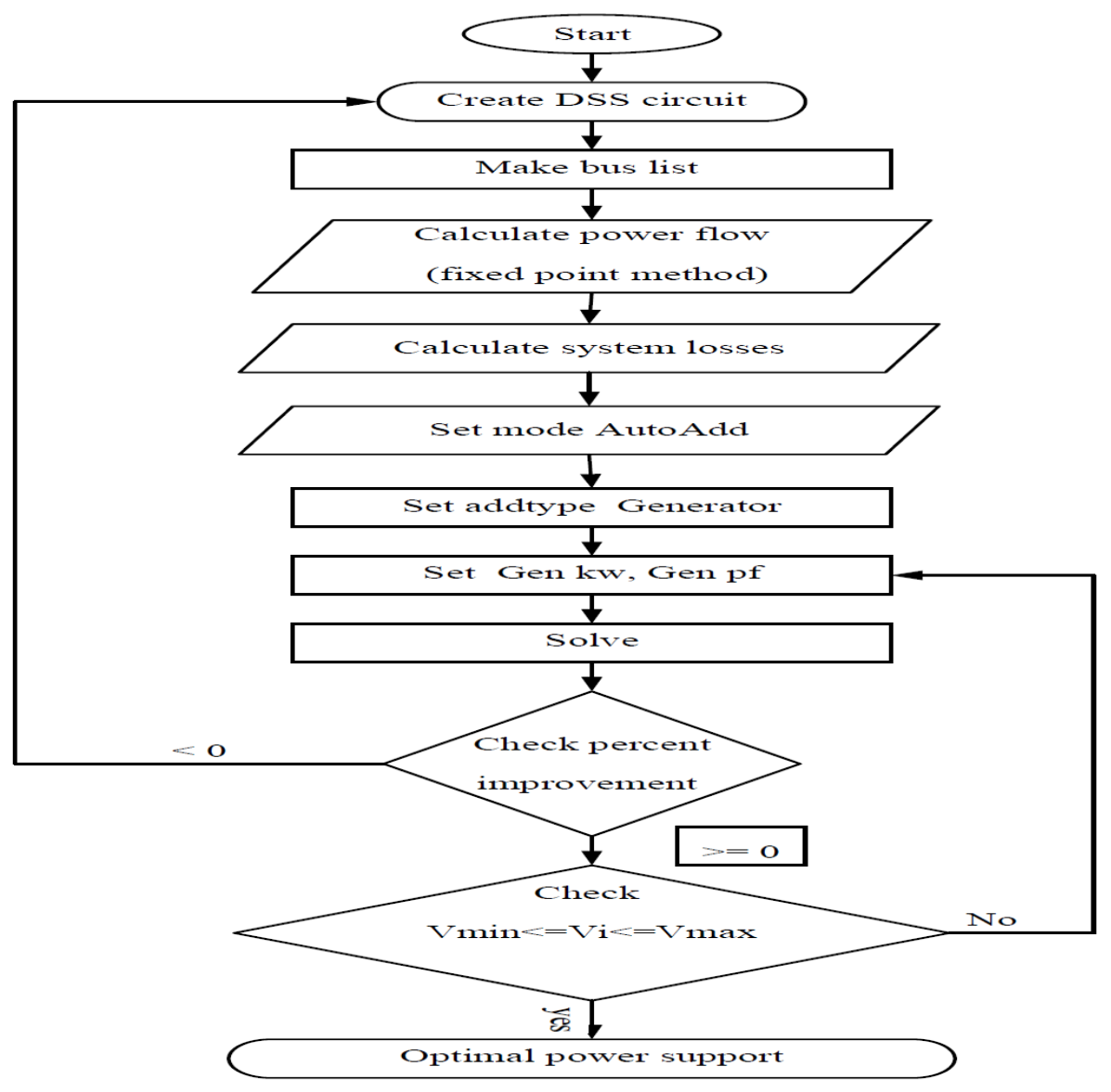

Figure 4: Optimization Using AutoAdd

\section{Particle swarm optimization algorithm}

PSO technology is used to determine the best solution to the multi-objective problem of the location and size of distributed generators. PSO is an evolutionary mathematical technology. This technology was developed by simulating simplified social models.

(The idea of the algorithm is based on the kinetic and social behavior of swarms (birds and fish) through the idea of searching for food. The flock of birds searches for food from one place to another. Information is transmitted between them during the search for the best place for food. In addition, when you explore the flock of birds about a good place for the quality of food, it uses this place to get the best food. Thus, the algorithm works in two processes, the search process and the Repetition process, based on the best solutions within the specified search space [17].

This algorithm consists of particles (swarm population) that move within the specified search area. The algorithm is configured randomly from the number of particles. These particles depend on the speed and position of the particle, as it is updated based on the previous cases of the best position of the particle and its symbol (Pbest) and on the best position of the particles in the entire swarm and symbolizes it (Gbest) as shown in Figure 5. Particle position and velocity are expressed by:Xi = $(x i 1, x i 2, \ldots, X i d)^{T}, V i=(v i 1, v i 2, \ldots, V i d)^{T}$, respectively where $i=1,2, \ldots, n$, and $d$ is the size of the population. According to the dimensions of the problem, the position and velocity of the particles are adjusted until the termination conditions are met. This modification can be explained by the concept of velocity, where the velocity of each particle is modified by the following Eq. (7) and Eq. (8) [18-20]: 


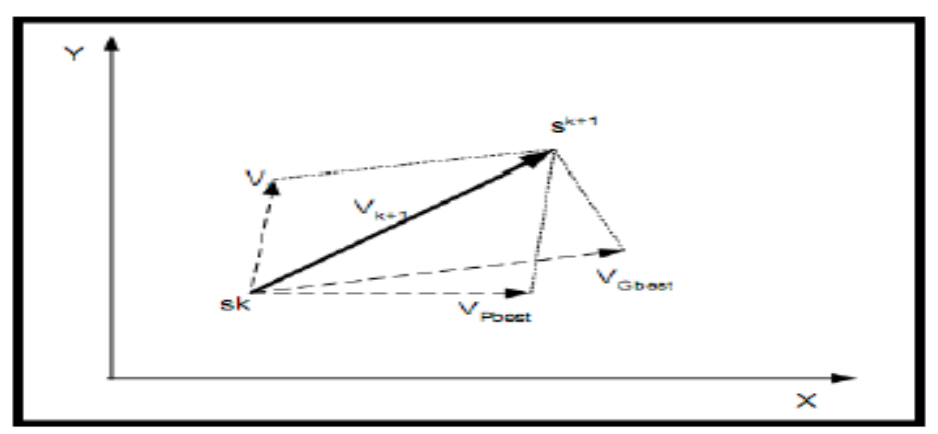

Figure 5: The concept of the search process in PSO

$$
\begin{gathered}
V_{i, d}^{k+1}=w V_{i, d}^{k}+c 1 . \operatorname{rand}_{1}^{k} \cdot\left(\text { pbest }_{i, d}^{k}-X_{i, d}^{k}\right)+c 2 \cdot \operatorname{rand}_{2}^{k} \cdot\left(\text { gbest }_{i, d}^{k}-X_{i, d}^{k}\right) \\
X_{i, d}^{k+1}=X_{i, d}^{k}+V_{i, d}^{k+1} \\
i=1,2,3, \ldots n, \quad d=1,2, \ldots . m .
\end{gathered}
$$

Where, $V_{i, d}^{k}$ and $V_{i, d}^{k+1}$ are current particle velocity and modified search points. $X_{i, d}^{k}$ and $X_{i, d}^{k+1}$ are Current particle position and adjusted search points. $c 1$ and $c 2$ are constant acceleration coefficients. $\operatorname{rand}_{1}^{k}$ and $\operatorname{rand}_{2}^{k}$ are random numbers, which are distributed according to the regular distribution within a period $(0,1), V$ Pbest and VGbest are velocity based on Pbest Gbest respectively, $(n)$ and $(m)$ are a number of the particles in a group and members in a particle respectively. To improve the performance and efficiency of the algorithm, the weight of inertia is added to the particle velocity update Eq. (7) and denoted by w, as shown in Eq. (9).

$$
W_{i}=W_{\max }-\left(\frac{W_{\max }-W_{\min }}{k_{\max }}\right) \times k
$$

Where $W$ is the weight of inertia, $k_{\max }$ and $k$ are the maximum and current iteration, $W_{\max }$ and $W_{\min }$ are the maximum and minimum weights, respectively. The flowchart of the particle swarm optimization is shown in Figure 6.

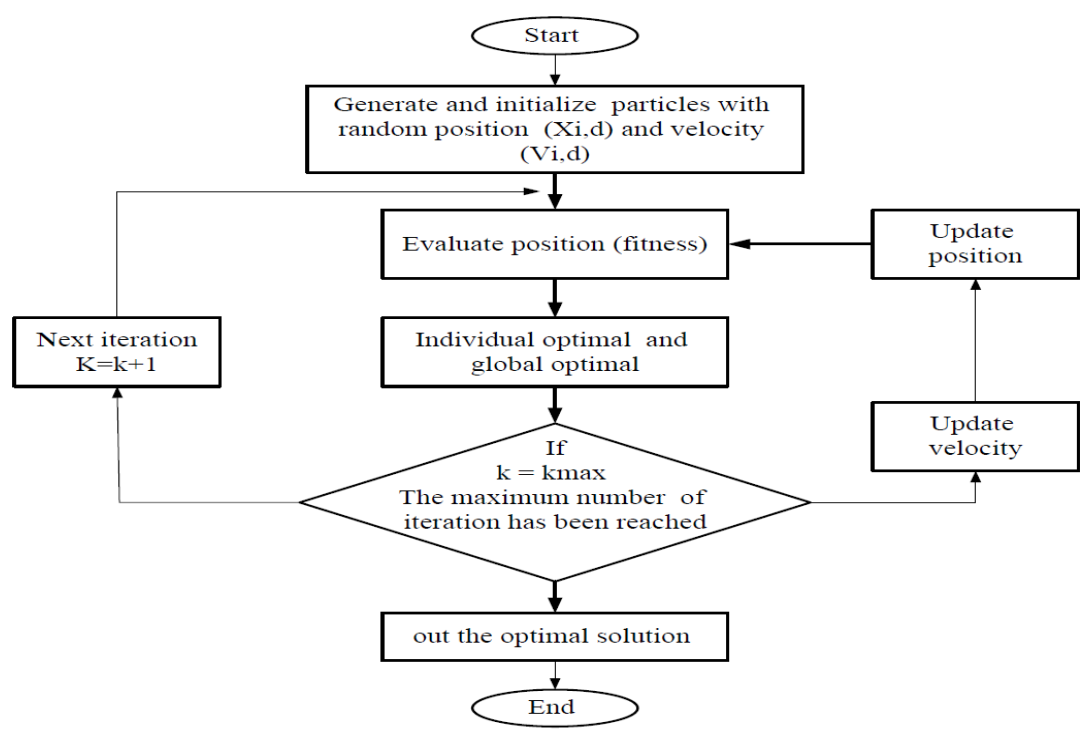

Figure 6: Flowchart of PSO 


\section{ANALYSIS AND RESULTS}

\section{Test system}

The single-line IEEE 33-bus radial distribution system illustrated in Figure 7 is chosen. System configuration is dependent on an operating voltage of $100 \mathrm{MVA}, 12.66 \mathrm{kVA}$ (L-L), and $60 \mathrm{~Hz}$. Load and impedance data is provided at [9]. The total real and interactive power loads on the system are $3715 \mathrm{~kW}$ and $2300 \mathrm{kV}$.

Voltage levels and load currents were calculated using the fixed-point repeat method. A summary of the energy flow obtained is given in Figure 8 and Table I. The results were identical to the results obtained by the proposed methods [21-23].

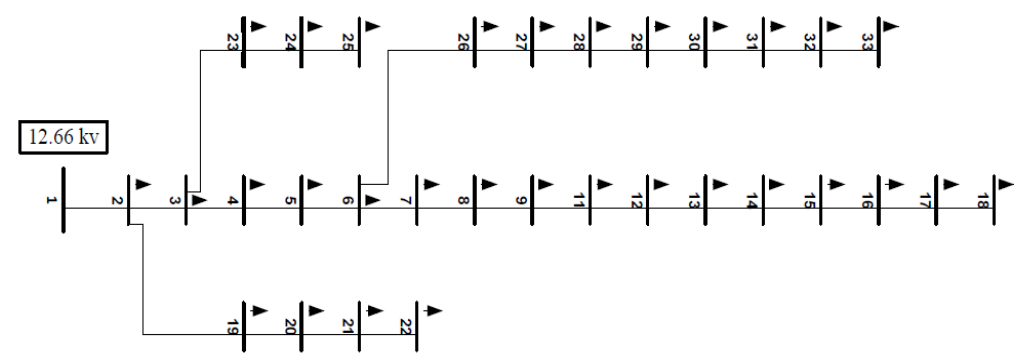

Figure 7: IEEE 33bus test distribution system

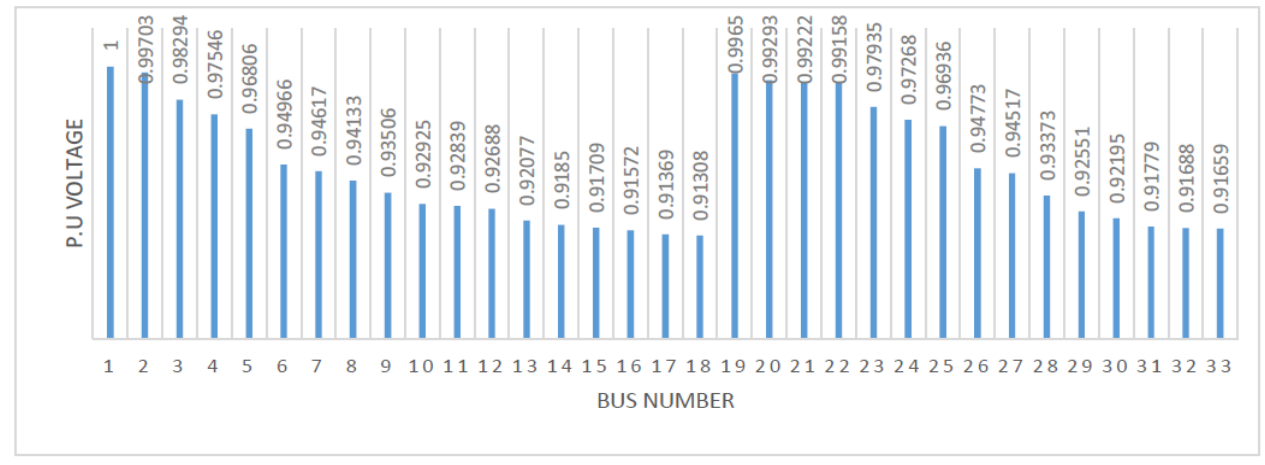

Figure 8: P.U bus voltage of IEEE 33-test system

TABLE I: Summary report of energy flow for the IEEE 33 bus test system using a fixed-point algorithm compared with other algorithms

\begin{tabular}{|c|c|c|c|c|c|}
\hline \multirow[t]{2}{*}{ Algorithms } & \multicolumn{2}{|c|}{ Total load } & \multirow{2}{*}{$\begin{array}{c}\text { Power } \\
\text { losses } \\
\text { kW }\end{array}$} & \multirow{2}{*}{$\begin{array}{c}\text { Minimum } \\
\text { voltage } \\
\text { on the feeder } \\
\text { (p.u.) }\end{array}$} & \multirow{2}{*}{$\begin{array}{c}\text { Location of } \\
\text { minimum } \\
\text { voltage }\end{array}$} \\
\hline & $k W$ & $\begin{array}{l}\boldsymbol{k} \boldsymbol{V} \\
\boldsymbol{A r}\end{array}$ & & & \\
\hline $\begin{array}{c}\text { 33-bus } \\
\text { Proposed algorithm }\end{array}$ & 3715 & $\begin{array}{c}230 \\
0\end{array}$ & 202.66 & 0.91308 & Bus 18 \\
\hline $\begin{array}{l}\text { 33-bus Artificial Bee } \\
\text { Colony Algorithm [21] }\end{array}$ & 3715 & $\begin{array}{c}230 \\
0\end{array}$ & 202.71 & 0.9131 & Bus 18 \\
\hline 33-bus PGSA [22] & 3715 & $\begin{array}{c}230 \\
0\end{array}$ & 202.71 & 0.9131 & Bus 18 \\
\hline $\begin{array}{l}\text { 33-bus backward/forward } \\
\text { sweep (CYMDIST) [23] }\end{array}$ & 3715 & $\begin{array}{c}230 \\
0\end{array}$ & 202.71 & 0.913 & Bus 18 \\
\hline
\end{tabular}

Table II indicates a list of solutions presented by researchers in [3, 24-26] to choose three distributed generators in terms of the best location, size, and ratio to improve losses on the 33-bus system.

The results presented in Table II demonstrate the efficiency and effectiveness of the proposed algorithms and their superiority over the published methods. 
TABLE II: Comparing the power flow analysis after adding 3 DGs using (Autoadd) and (PSO) method, and comparing it with other methods

\begin{tabular}{cccccc}
\hline \hline Method & $\begin{array}{c}\text { P loss, DG } \\
(\mathbf{k W})\end{array}$ & $\begin{array}{c}\text { Min } \\
\text { voltage }\end{array}$ & DG location & DG size (MW) & $\begin{array}{c}\text { Power } \\
\text { factor } \\
\text { (PF) }\end{array}$ \\
\hline GA [24] & 106.3 & 0.9809 & $11,29,30$ & $1.5,0.4228,1.0714$ & 1 \\
\hline PSO [24] & 105.35 & 0.9806 & $13,32,8$ & $0.9816,0.8297,1.1768$ & 1 \\
\hline REPSO[25] & 76.91 & 0.9694 & $6,14,31$ & $1.2274,0.6068,0.6870$ & 1 \\
\hline GAMS[3] & 72.79 & 0.968 & $14,24,30$ & $0.7709,1.0969,1.0658$ & 1 \\
\hline $\begin{array}{c}\text { Proposed } \\
\text { AutoAdd }\end{array}$ & 71.4 & 0.9693 & $14,24,30$ & $0.7305,1.0852$, & 1 \\
\hline BSA [26] & 21.3178 & 0.9918 & $30,24,13$ & 1.1009 & 0.85 \\
\hline $\begin{array}{c}\text { Proposed } \\
\text { AutoAdd }\end{array}$ & 16.7 & 0.9924 & $30,11,24$ & $1.190,0.990,0.802$ & 0.85 \\
\hline $\begin{array}{c}\text { Proposed } \\
\text { PSO }\end{array}$ & 19.2 & 0.9799 & $9,30,24$ & $1.071,0.9095,0.9605$ & 0.85 \\
\hline
\end{tabular}

Figure 9 and Table III show the results of the network analysis after adding 3DGs with $\mathrm{pf}=0.85$. The voltage profile was significantly improved for all bus bars, and losses are minimized in both methods. Through the results, it could be noted that the method (Autoadd) outperformed over (PSO) in terms of improving the voltage profile and loss reduction; the reason is that the improved voltage and the reduction of losses depend on the location and the optimum size of the distributed generators.

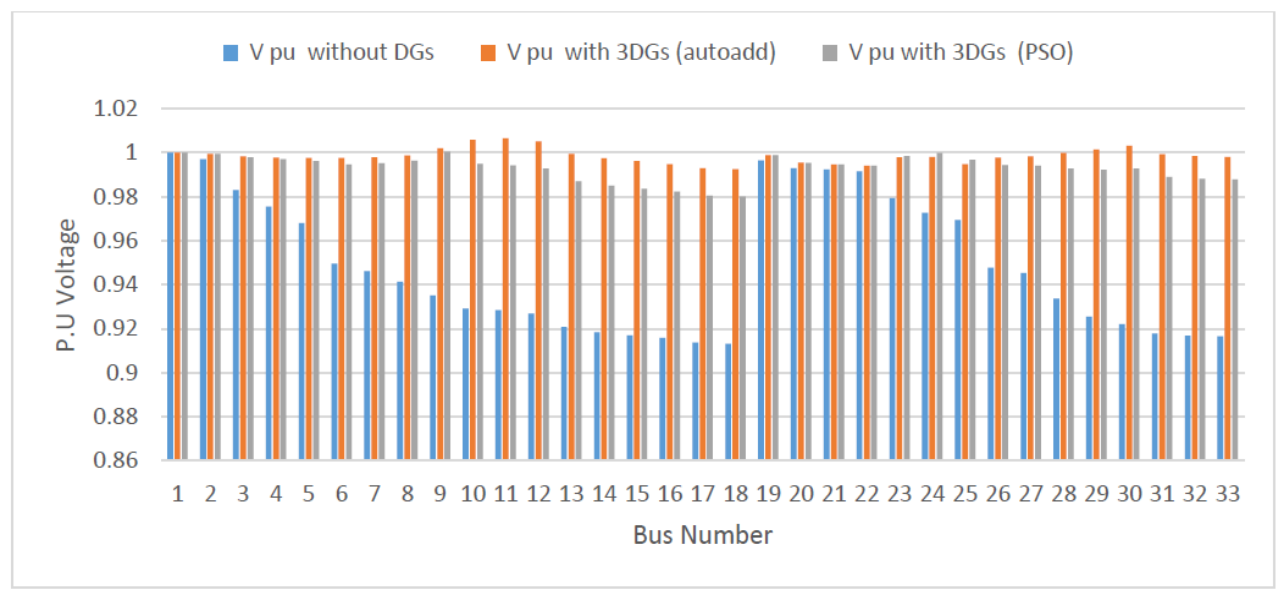

Figure 9: P.U bus voltage before and after adding 3DGs by PSO and Autoadd

TABLE III: P.U bus voltage and losses before and after adding 3DGs by Autoadd and PSO

\begin{tabular}{cccccc}
\hline \hline \multirow{2}{*}{ Without DGs } & \multicolumn{3}{c}{ With 3DGs } \\
\cline { 2 - 5 } Losses $\boldsymbol{k W}$ & $\begin{array}{c}\text { Min voltage } \\
\text { (bus) }\end{array}$ & Losses $\boldsymbol{k W}$ & $\begin{array}{c}\text { Min voltage } \\
\text { (bus) }\end{array}$ & Losses $\boldsymbol{k W}$ & $\begin{array}{c}\text { Min voltage } \\
\text { (bus) }\end{array}$ \\
\hline 202.66 & $0.91308(18)$ & 16.7 & $0.9924(18)$ & 19.2 & $(18)$ \\
\hline
\end{tabular}

\section{Case study: Practical network}

One feeder is selected from the Al-jamiea distribution network in AL-Diwaniya city, $11 \mathrm{kV} 6.63$ MW, which consists of 31 buses Figure 10 shows the one-line diagram of the distribution system under consideration. The system data are given in Appendix A. The voltage limits are defined as Vmin $=0.95$ p.u and Vmax $=1.05$ p.u. Three different loads are considered in this study 100, 80, and $60 \%$.

The energy flow of the real network is analyzed by the proposed method and the results of the analysis appeared as shown in Table IV. 


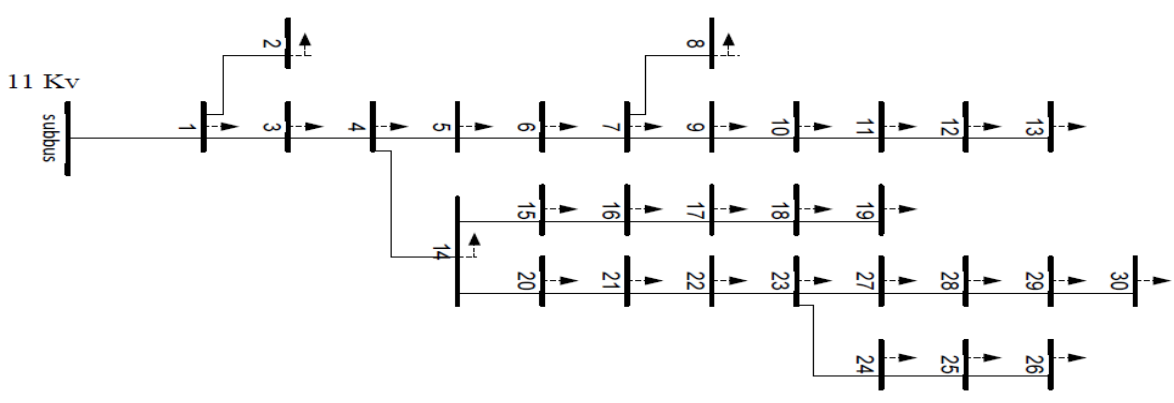

Figure 10: Feeder of Al-jamiea distribution network

TABLE IV: Result of power flow of the Al-jamiea distribution network for three loads.

\begin{tabular}{cccc}
\hline \hline \% load & Total load (kW) & kW loss & Min voltage (bus) \\
\hline $100 \%$ load & 6630 & 306.2 & $0.9392(30)$ \\
\hline $80 \%$ load & 5304 & 191.1 & $0.95201(30)$ \\
\hline $60 \%$ load & 3978 & 105 & $0.96445(30)$ \\
\hline
\end{tabular}

After analyzing the energy flow, it was proposed to add three distributed generators to improve the voltage profile and reduce losses. The optimum location and size of the distributed generators were determined by the proposed methods (Autoadd) and (PSO) as shown in Table V.

TABLE V: The optimal location and size of 3DGs extracted by the proposed methods

\begin{tabular}{|c|c|c|c|c|c|c|}
\hline \multirow[b]{2}{*}{$D G$} & \multicolumn{3}{|c|}{ AutoAdd } & \multicolumn{3}{|c|}{ PSO } \\
\hline & $\begin{array}{c}\text { DG size } \\
(M W)\end{array}$ & $\begin{array}{c}\text { Location of } \\
D G\end{array}$ & $P F$ & $D G$ size $(M W)$ & $\begin{array}{c}\text { Location of } \\
D G\end{array}$ & $P F$ \\
\hline Diesel engine 1 & 1.2 & 28 & 0.85 & 1.2 & 20 & $\begin{array}{c}0.8 \\
5\end{array}$ \\
\hline Diesel engine 2 & 1 & 11 & 0.85 & 1 & 28 & $\begin{array}{c}0.8 \\
5\end{array}$ \\
\hline Diesel engine 3 & 0.8 & 18 & 0.85 & 0.8 & 6 & $\begin{array}{c}0.8 \\
5\end{array}$ \\
\hline Total generation & $3 \mathrm{MW}$ & & & $3 \mathrm{MW}$ & & \\
\hline
\end{tabular}

After adding the distributed generators, the voltage profile for all bus bars of the Al-jamiea distribution network has been improved for three variable loads, as shown in Figures 11-13. In addition, system losses decreased significantly due to the presence of distributed generators at ideal locations near the load. Therefore, the stress on the lines was reduced, and consequently, the losses were reduced in both methods. The results showed the superiority of the (Autoadd) method in terms of improving the voltage shape and reducing losses in all cases, as shown in Table VI.

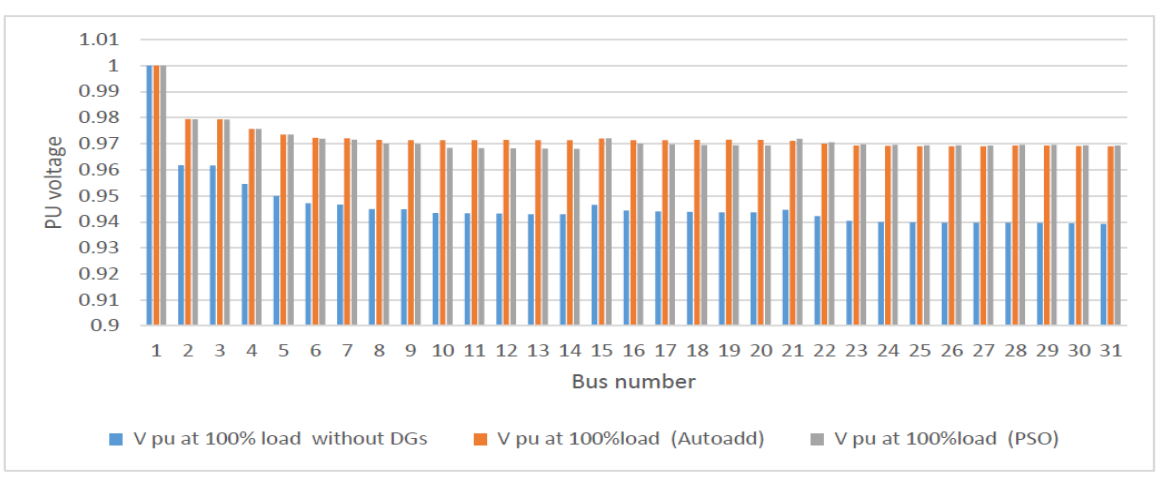

Figure 11: Voltage profile for all buses at $100 \%$ load 


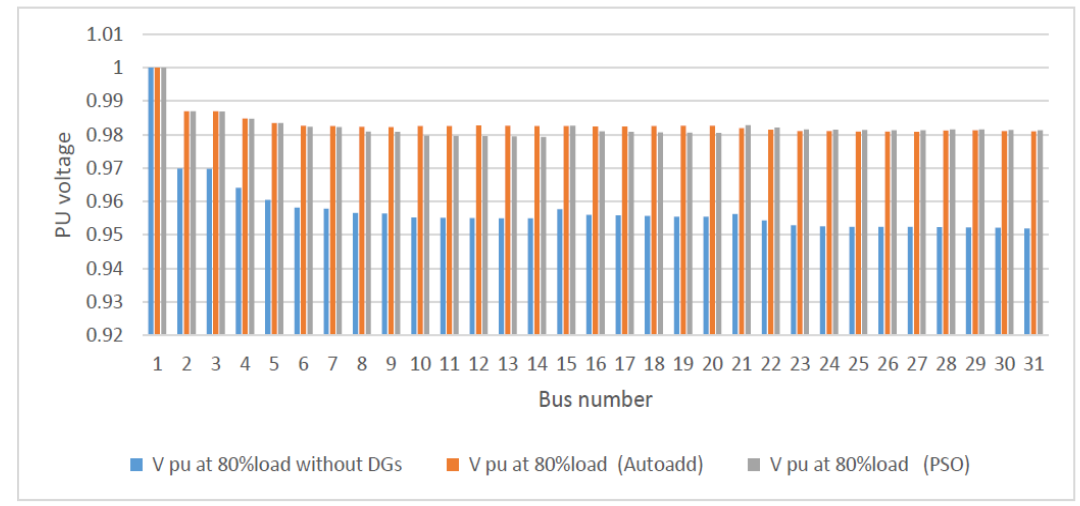

Figure 12: Voltage profile for all buses at $80 \%$ load

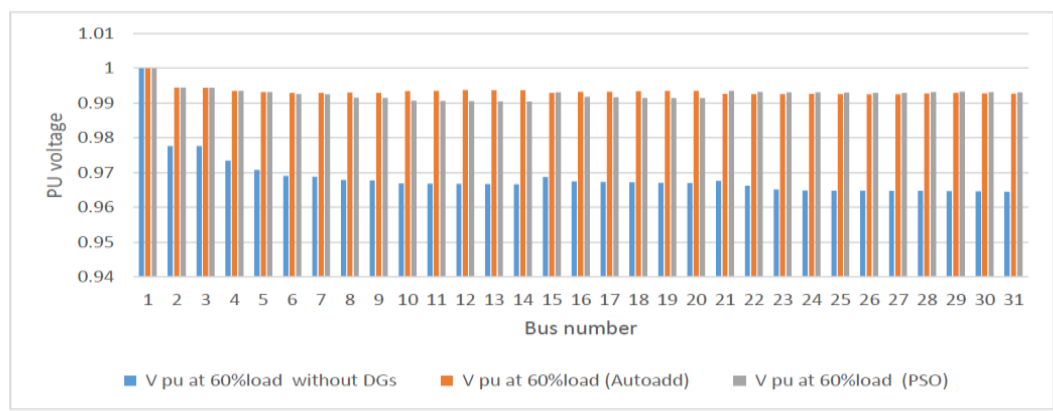

Figure 13: Voltage profile for all buses at $60 \%$ load

TABLE VI:Results of losses and minimum voltage of the proposed method (Autoadd) and (PSO) of the Al-jamiea distribution network for three loads

\begin{tabular}{|c|c|c|c|c|c|c|}
\hline \multirow[b]{2}{*}{$\begin{array}{c}\% \\
\text { load }\end{array}$} & \multicolumn{2}{|c|}{ 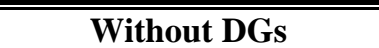 } & \multicolumn{2}{|c|}{ Autoadd } & \multicolumn{2}{|c|}{$\begin{array}{l}\text { PSO } \\
\end{array}$} \\
\hline & $k W$ loss & $\begin{array}{c}\text { Min voltage } \\
\text { (bus) }\end{array}$ & $\begin{array}{c}\text { kW loss } \\
\text { with } D G s\end{array}$ & $\begin{array}{c}\text { Min voltage } \\
\text { (bus) }\end{array}$ & $\begin{array}{c}k W \text { loss with } \\
D G s\end{array}$ & $\begin{array}{c}\text { Min voltage } \\
\text { (bus) }\end{array}$ \\
\hline $\begin{array}{c}100 \\
\%\end{array}$ & 306.2 & $0.93921(30)$ & 82.1 & $\begin{array}{c}0.96895 \\
(26)\end{array}$ & 87.3 & $0.96805(13)$ \\
\hline $\begin{array}{l}80 \\
\%\end{array}$ & 191.1 & $0.95201(30)$ & 31.9 & $\begin{array}{c}0.98088 \\
(26)\end{array}$ & 35.3 & $0.97938(13)$ \\
\hline $\begin{array}{l}60 \\
\%\end{array}$ & 105 & $0.96445(30)$ & 5.9 & $\begin{array}{c}0.99252 \\
\text { (26) }\end{array}$ & 7.8 & 0.99045 (13) \\
\hline
\end{tabular}

\section{Conclusions}

The aim of this work is to reduce losses and to improve voltage profile in the distribution networks. The fixed-point iteration method is used to analyze the power flow within OpenDSS because of its efficiency, accuracy, and speed. OpenDSS is considered an important program because it supports the analysis of integrated distributed generators; it specializes in the fields of microgrids and it supports many features of models of microgrids. A new search algorithm (Autoadd) was introduced along with the (PSO). The proposed methods determine the optimum location for distributed generators and their size with minimal losses. These algorithms have been applied to (IEEE 33-bus test system) and realistic network (for three variable loads) and validating their validity and effectiveness by comparing their results with each other as well as with published results.

The proposed AutoAdd method proved its superiority and speed in determining the optimal location for (DGs) with minimal losses. This method is one of the easiest methods and is highly efficient compared to other algorithms. This method is a feature of OpenDSS for locating generators as well as capacitors and it is able to handle all sizes of distribution systems. Consequently, losses were reduced to a minimum due to the presence of distributed generators in the best location, size, and near loads. 
Appendix A

TABLE A-I: The line and load data for the Al_Jamiea distribution network

\begin{tabular}{|c|c|c|c|c|c|c|}
\hline section No. & From Bus & To Bus & Load $(\mathbf{k W})$ & load (KVAr) & 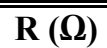 & $\bar{X}(\Omega)$ \\
\hline 1 & Sub bus & 1 & 212.5 & 131.7 & 0.3681 & 0.4493 \\
\hline 2 & 1 & 2 & 212.5 & 131.7 & 0.02375 & 0.02899 \\
\hline 3 & 1 & 3 & 340 & 210.7 & 0.07481 & 0.09131 \\
\hline 4 & 3 & 4 & 212.5 & 131.7 & 0.04987 & 0.060879 \\
\hline 5 & 4 & 5 & 212.5 & 131.7 & 0.09618 & 0.1174 \\
\hline 6 & 5 & 6 & 212.5 & 131.7 & 0.0178 & 0.0217 \\
\hline 7 & 6 & 7 & 212.5 & 131.7 & 0.0712 & 0.0869 \\
\hline 8 & 7 & 8 & 212.5 & 131.7 & 0.0356 & 0.0434 \\
\hline 9 & 7 & 9 & 212.5 & 131.7 & 0.0973 & 0.1188 \\
\hline 10 & 9 & 10 & 340 & 210.7 & 0.00855 & 0.0104 \\
\hline 11 & 10 & 11 & 212.5 & 131.7 & 0.0174 & 0.0211 \\
\hline 12 & 11 & 12 & 212.5 & 131.7 & 0.024 & 0.029 \\
\hline 13 & 12 & 13 & 85 & 52.67 & 0.0308 & 0.0376 \\
\hline 14 & 4 & 14 & 212.5 & 131.7 & 0.0594 & 0.0724 \\
\hline 15 & 14 & 15 & 212.5 & 131.7 & 0.1306 & 0.159 \\
\hline 16 & 15 & 16 & 212.5 & 131.7 & 0.0183 & 0.0223 \\
\hline 17 & 16 & 17 & 212.5 & 131.7 & 0.0235 & 0.0287 \\
\hline 18 & 17 & 18 & 212.5 & 131.7 & 0.0214 & 0.0261 \\
\hline 19 & 18 & 19 & 212.5 & 131.7 & 0.01544 & 0.0188 \\
\hline 20 & 14 & 20 & 340 & 210.7 & 0.0475 & 0.05798 \\
\hline 21 & 20 & 21 & 212.5 & 131.7 & 0.0736 & 0.089 \\
\hline 22 & 21 & 22 & 212.5 & 131.7 & 0.0594 & 0.0724 \\
\hline 23 & 22 & 23 & 212.5 & 131.7 & 0.0178 & 0.0217 \\
\hline 24 & 23 & 24 & 212.5 & 131.7 & 0.0214 & 0.0261 \\
\hline 25 & 24 & 25 & 212.5 & 131.7 & 0.01116 & 0.0136 \\
\hline 26 & 25 & 26 & 85 & 52.67 & 0.0157 & 0.0191 \\
\hline 27 & 23 & 27 & 212.5 & 131.7 & 0.0174 & 0.0211 \\
\hline 28 & 27 & 28 & 212.5 & 131.7 & 0.00878 & 0.0107 \\
\hline 29 & 28 & 29 & 212.5 & 131.7 & 0.022 & 0.027 \\
\hline 30 & 29 & 30 & 340 & 210.7 & 0.0285 & 0.0347 \\
\hline
\end{tabular}

\section{References}

[1] P. K. Kaushal and M. Tomar, Real and reactive power loss minimization of IEEE-33 bus by optimal DG placement using LSO in RDS, in 2017 International Conference on Energy, Communication, Data Analytics and Soft Computing (ICECDS), 2017. https://doi.org/10.1109/ICECDS.2017.8389767

[2] P. Prakash and D. K. Khatod, Optimal sizing and siting techniques for distributed generation in distribution systems: A review, Renew. Sustain. Energy. Rev., $57 \quad$ (2016) 111-130. https://doi.org/10.1016/j.rser.2015.12.099

[3] O. D. Montoya, W. Gil-González, and L. F. Grisales-Noreña, An exact MINLP model for optimal location and sizing of DGs in distribution networks: A general algebraic modeling system approach, Ain Shams Eng. J., 11 (2020) 409-418. https://doi.org/10.1016/j.asej.2019.08.011

[4] H. R. Galiveeti, A. K. Goswami, and N. B. D. Choudhury, Impact of plug-in electric vehicles and distributed generation on reliability of distribution systems, Eng. Sci. Technol. an Int. J., 21 (2018) 50-59. https://doi.org/10.1016/j.jestch.2018.01.005

[5] L. F. Grisales and B. J. Restrepo Cuestas, Location and sizing of distributed generation: A review, Cienc. e Ing. Neogranadina, 27 (2017) 157-176. https://doi.org/10.18359/rcin.2344

[6] F. U. Din, A. Ahmad, H. Ullah, A. Khan, T. Umer, and S. Wan, Efficient sizing and placement of distributed generators in cyber-Physical power systems, J. Syst. Archit., 97 (2019) 197-207. https://doi.org/10.1016/j.sysarc.2018.12.004

[7] Z. Ullah, S. Wang, and J. Radosavljević, A novel method based on PPSO for optimal placement and sizing of distributed generation, IEEJ Trans. Electr. Electron. Eng., 14 (2019) 1754-1763. https://doi.org/10.1002/tee.23001 
[8] S. Essallah, A. Khedher, and A. Bouallegue, Integration of distributed generation in electrical grid: Optimal placement and sizing under different load conditions, Comput. Electr. Eng., 79 (2019) 106461. https://doi.org/10.1016/j.compeleceng.2019.106461

[9] R. B. Magadum and D. B. Kulkarni, Optimal Placement and Sizing of Multiple Distributed Generators using Fuzzy Logic, 5th Int. Conf. Electr. Energy Syst. ICEES 2019, no. February, (2019) 1-6. https://doi.org/10.1109/ICEES.2019.8719240

[10] S. Das, D. Das, and A. Patra, Operation of distribution network with optimal placement and sizing of dispatchable DGs and shunt capacitors, Renew. Sustain. Energy Rev., 113 (2017) 109219. https://doi.org/10.1016/j.rser.2019.06.026

[11] A. T. Davda and B. R. Parekh, System impact analysis of renewable distributed generation on an existing radial distribution network, in 2012 IEEE Electrical Power and Energy Conference, 2012. https://doi.org/10.1109/EPEC.2012.6474936

[12] R. C. Dugan and T. E. McDermott, An open source platform for collaborating on smart grid research, IEEE Power Energy Soc. Gen. Meet., no. Ivvc, pp. 1-7, 2011. https://doi.org/10.1109/PES.2011.6039829

[13] R. C. Dugan, Institute, EPR OpenDSS Manual, https://sourceforge.net/projects/electricdss. Train. Mater., pp. 1-184, 2019.

[14] C. Wang et al., Analysis on the impact of DG on distribution network reconfiguration, Tianjin Daxue Xuebao (Ziran Kexue yu Gongcheng Jishu Ban)/Journal Tianjin Univ. Sci. Technol. 47 (2014) 189-194. https://doi.org/10.11784/tdxbz201206043

[15] S. Singh, D. Shukla, and S. P. Singh, Peak demand reduction in distribution network with smart gridenabled CVR, in 2016 IEEE Innovative Smart Grid Technologies-Asia (ISGT-Asia), 2016. https://doi.org/10.1109/ISGT-Asia.2016.7796476

[16] R. C. Dugan and D. Montenegro, The open distribution system simulator (OpenDSS): Reference guide, Electr. Power Res. Inst., 2019.

[17] D. P. Rini, S. M. Shamsuddin, and S. S. Yuhaniz, Particle swarm optimization: technique, system and challenges, Int. J. Comput. Appl., 14 (2011) 19-26. https://doi.org/10.5120/ijais-3651

[18] R. H. Al-Rubayi and M. B. Eesee, Optimal Location and Parameter Setting of STATCOM Device Based PSO for Iraqi Grid Voltage Profile Enhancement and Power Losses Minimizing, Eng. Technol. J., 37 (2019) 60-69. https://doi.org/10.30684/etj.37.2A.4

[19] V. V. S. N. Murty and A. Kumar, Impact of D-STATCOM in distribution systems with load growth on stability margin enhancement and energy savings using PSO and GAMS, Int. Trans. Electr. Energy Syst., 28 (2018) 1-24. https://doi.org/10.1002/etep.2624

[20] H. Wu, X. Liu, and M. Ding, Dynamic economic dispatch of a microgrid: Mathematical models and solution algorithm, Int. J. Electr. Power Energy Syst., $63 \quad$ (2014) 336-346. https://doi.org/10.1016/j.ijepes.2014.06.002

[21] R. S. Rao, S. V. L. Narasimham, and M. Ramalingaraju, Optimization of distribution network configuration for loss reduction using artificial bee colony algorithm, Int. J. Electr. Power Energy Syst. Eng., 1 (2008) 116-122.

[22] A. K. Sarma and K. M. Rafi, Optimal selection of capacitors for radial distribution systems using plant growth simulation algorithm, Int. J. Adv. Sci. Technol., 30 (2011) 43-54.

[23] T. M. Abdul-Wahhab and O. A. Abdullah, Simulation and Contingency Analysis of a Distributed Network in Iraq, M. Sc. Thesis, University of Technology, September, 2015.

[24] A. Mohamed and M. Kowsalya, Optimal size and siting of multiple distributed generators in distribution system using bacterial foraging optimization, Swarm Evol. Comput., 15 (2014) 58-65. https://doi.org/10.1016/j.swevo.2013.12.001

[25] J. J. Jamian, M. W. Mustafa, and H. Mokhlis, Optimal multiple distributed generation output through rank evolutionary particle swarm optimization, Neurocomputing, $152 \quad$ (2015) 190-198. https://doi.org/10.1016/j.neucom.2014.11.001

[26] D. S. K. Kanth, N. S. R. Reddy, and R. S. G. Reddy, Optimal placement \& sizing of DG's using backtracking search algorithm in IEEE 33-bus distribution system, Int. Conf. Comp. Meth. Comm., (2017) 163-169. https://doi.org/10.1109/ICCMC.2017.8282667 2017 